\title{
Hvor mye medievold er for mye?
}

Etter Irak-krigen har debatten gått blant internasjonale journalister, politikere og medieforskere: Hvor voldelige bilder skal mediene vise fra slagmarken?

Tine Ustad Figenschou er redaksjonsmedlem i Babylon og arbeider for tiden som høgskolelektor i journalistikk ved Høgskolen i Oslo. 
TEKST: Tine Ustad Figenschou

«Og dette er det bildet den arabiske verda har fätt av krigen: Scenene grin mot oss, er noko heilt anna enn den pene krigen. Rått og uslad$d a$, dette er dei første noerbilda av sivile offer [...] Ei kvinne frå Røde Kors er intervjua, ho fortell at køen av hjelpetrengande vert treft. Det er kaos og tett filming, altfor tett filming. Forferdelege bilde av drepne og skadde. For oss $i$ NRK ville det vere uråd å bruke dei fleste bilda, andre stasjonar sladdar det verste og kjøper ein del av råstoffet Al-Jazeera har.»1

Dette skriver NRK-journalist Sigrun Slapgard om krigsdekningen på Al Jazeera under krigen i Irak. Slapgards skildring peker på to viktige trekk ved mediedekningen fra Irak: For det første, de arabiske satellittkanalene viste flere og mer groteske bilder av ofrene for krigen. For det andre, selv om disse bildene var tilgjengelige for vestlige medier, valgte de fleste vestlige kanalene å ikke sende dem. De siste par årene har temaet krigsjournalistikk blitt tatt opp på en rekke internasjonale konferanser. Debatten har i stor grad dreid seg om hvor mye vold og ofre for vold mediene kan vise: Viste de arabiske mediene for mye blod og lemlestede ofre? Viste de vestlige mediene en finpusset, glatt og blodløs krig? Hvor mye vold er for mye og hvor lite er for lite? Det finnes ingen absolutte svar.

Hva er medievold? ${ }^{2}$ Det finnes lite komparativ global forskning på medievold. I medielitteraturen er begrepet "vold" forstått forskjellig hos ulike forfattere, og det finnes ingen bred enighet om begrepet. Noen forskere opererer med en snever definisjon av vold - utelukkende som fysisk vold (for eksempel drap, slag eller spark). Andre utvider begrepet til også å inneholde aggresjon og verbal vold (for eksempel utskjelling og mobbing), mens forskerne med den videste versjonen av begrepet også inkluderer strukturell vold ${ }^{3}$ som er forårsaket av sult og krig. Ifølge Vettenranta fører mangelen på felles forståelse av begrepet til at det er vanskelig å sammenligne studier av medievold. Denne artikkelen bruker medievold i betydningen fysisk vold i faktaprogrammer. Den offentlige debatten om medievold har derimot i hovedsak fokusert på fysisk fiksjonsvold - voldelige filmer, Tv-serier eller dataspill. Vold i nyheter og faktaprogrammer har ikke vært forsket på i tilsvarende grad. Vi vet derfor lite om hvilke konsekvenser medienes framstilling av vold og ofre i nyhetene har på publikum.

Sivile ofre i moderne krigføring: I dag fokuserer mediene i større grad på sivile befolkninger som ofre for konflikter og 
kriger enn tidligere. Dette kan være en konsekvens av at de fleste ofrene i moderne krigføring er sivile og dette er en utfordring for mediene. ${ }^{4}$ En annen forkaring kan være at mange krigsjournalister $\mathrm{i}$ dag anser det som en av sine viktigste oppgaver $i$ en krigssituasjon å rapportere om hvordan krigen rammer sivile, kvinner og barn. Blant journalistene selv er det vokst fram en bevissthet om nødvendigheten av å vise "krigens sanne ansikt" som ofte forsvinner bak de stridende partenes propagandaversjoner av konflikten.

Innen medieforskningen betegnes dette økende fokuset på menneskelige lidelser i reportasjer fra fjerne og nære kriger og kriser som den globale medlidenhetsdiskursen - en betegnelse på nyhetsinnslag dominert av skildringer av forbrytelser mot menneskeheten, overgrep og vold mot uskyldige ofre. Siden slutten av den kalde krigen har vestlige politikere vekslet mellom politisk maktretorikk og en global medlidenhetsdiskurs for å legitimere internasjonale intervensjoner.5 Den globale medlidenhetsdiskursen i den vestlige verden utvikles $i$ et samspill mellom disse politikerne, media, publikum og de humanitære organisasjonene: Politikerne bruker hensynet til lidende sivilbefolkning for å legitimere sine handlinger, mediene sender oss bilder av nød og elendighet, mens en økende gruppe humanitære organisasjoner på sin side forsøker å hjelpe ofrene og bruker ofrene $i$ sine informasjonskampanjer for å engasjere publikum.

Mediefokuset på sivile ofre for krig og voldelige konflikter varierer likevel fra konflikt til konflikt. Medlidenhetsdiskursen var særlig tydelig under mediedekningen av Kosovo-konflikten i I999, der kosovo- albanske flyktningers lidelseshistorier dominerte krigsdekningen. ${ }^{6}$ På den annen side var bilder av irakiske ofre for krig og vold så godt som fraværende i den internasjonale mediedekningen fra Golf-krigen

\section{TV-nyhetene sender ansikter som vrir seg $i$ smerte, blodpøler og nocrbilder av avrevne lemmer.}

i I99I. Flere studier viser imidlertid at fokuset på menneskelig lidelse i mediene samlet sett har økt. Vi ser flere ofre for vold enn før og bildene har blitt grovere - TVnyhetene sender ansikter som vrir seg i smerte, blodpøler og nærbilder av avrevne lemmer.7 Bildene kan skape reaksjoner og empati hos publikum, men også apati, det man i medieforskningen kaller medlidenhetsutmattelse. Ifølge Vettenranta kan publikum bli likegyldige, med kortvarig og minimal interesse for katastrofene, som et resultat av at de ikke orker å ta inn alle inntrykkene. Som en konsekvens sender dermed de mediene som er (mest) opptatt av å tiltrekke seg flest mulig mottakere, mindre vold og katastrofer i perioder. ${ }^{8}$

\section{"Verdige" og "uverdige" medieofre}

Ifølge de humanitære organisasjonenes moralske idealer er det ingen sosiale, kulturelle eller geografiske grenser for hvilke ofre vi skal bry oss om. I politikken og i mediene derimot, er det mange ofre som aldri kvalifiserer som "verdige ofre". Konstruksjonen av "Det ideelle offer" er en kognitiv og kulturell konstruksjon. Mens ofrene for terrorangrepet mot New York ble æret med stillhet og medfølelse i hele den 


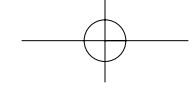

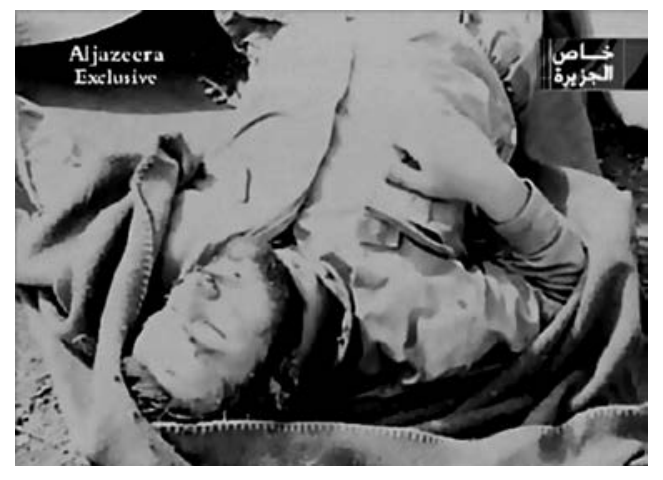

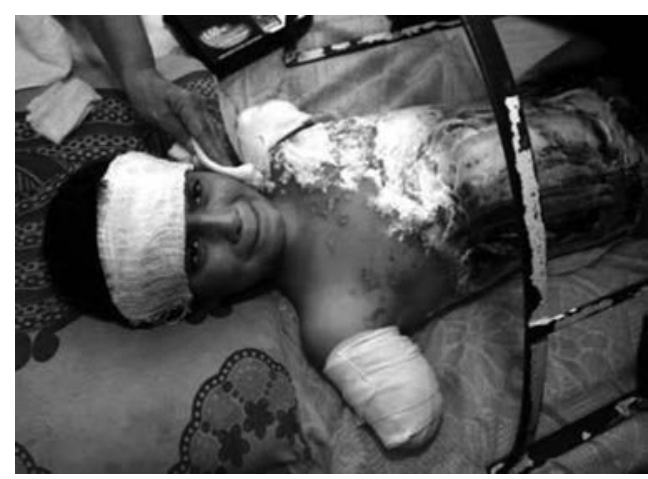

vestlige verden, er ofrene for borgerkriger $i$ Afrika som oftest glemt av omverdenen. Men man finner også noen fellestrekk: Mediene har blitt mer personfokuserte, og for å finne sterkest mulige bilder av sorg, smerte og redsel, griper man ofte til bilder av lidende kvinner, eldre eller små barn. Parallelt med denne nærgående journalistikken har det utviklet seg en mer distansert katastrofeestetikk, en estetisering av nyhetsinnslagene fra større katastrofer og kriser. Katastrofeestetikken (som var tydelig i innslagene fra terrorangrepene mot New York) kan til tider minne om moderne, impresjonistisk film - uten inhumane, smertelige sekvenser eller identifiserbare ofre slik vi vanligvis møter dem i nyhetene. ${ }^{9}$

Partene i en konflikt har ulike forståelser av hvem som er konfliktens verdige og uverdige ofre. De stridende partene vil

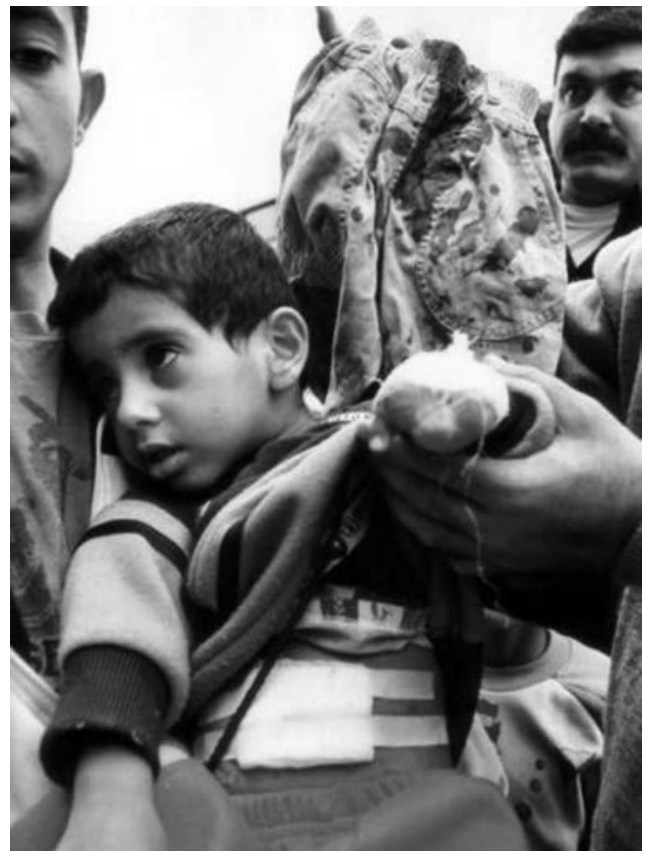

Mange journalister i dag anser det som sin viktigste oppgave i en krigssituasjon å rapportere om hvordan krigen rammer sivile, kvinner og barn.

alltid forsøke å fremstille den lidelsen som motstanderen er skyld i som umenneskelig, bestialsk og unødvendig. Når stormakter og stormaktskoalisjoner er i væpnet konflikt med andre og svakere motstandere er det dermed viktig for stormakten(e) å vektlegge at de(n) ikke vil skade sivilbefolkningen. I de seneste usA-ledede konflikter i Midtøsten var det også avgjørende for UsA å unngå at konflikten ble framstilt som Davids (Iraks og Afghanistans) kamp mot Goliat (USA). Amerikanske kommunikasjonsstrateger har derfor lagt press på mediene for å begrense både bilder av døde og skadde irakiske og afghanske soldater og landenes sivilbefolkning.

Under angrepet mot Afghanistan høsten 200I ble den USA-ledede angrepsretorikken støttet av en vektlegging av at angrepet skulle hjelpe den lidende sivilbefolkningen. Amerikanske fly slapp bomber, men 
også nødhjelp til en sultende og undertrykt afghansk sivilbefolkning. Under krigen i Afghanistan utøvde amerikanske myndigheter press mot internasjonale medier for å unngå reportasjer om sivile, afghanske ofre og lidelser. Den amerikanske administrasjonen var bekymret for at bilder av afghansk sivilbefolkning,

\section{De arabiske kanalene presenterte en} annen versjon av hendelsene i Irak enn deres vestlige konkurrenter.

som allerede før angrepene var truet av tørke, sult, undertrykkelse og brutalitet, skulle skape empati for det afghanske folket og som en følge svekke verdensopinionens støtte til det UsA-ledede angrepet. ${ }^{\text {Io }}$

Derfor vektla amerikanske myndigheter Talibans grove menneskerettighetsbrudd og framstilte koalisjonsstyrkenes angrep som frigjørende for kvinner og barn. De store amerikanske mediene fulgte i hovedsak denne linjen. ${ }^{\text {II }}$ Al Jazeera var eneste utenlandske Tv-kanal som fikk jobbe på bakken i de Taliban-kontrollerte områdene av Afghanistan. Kanalens mange dramatiske reportasjer fra Afghanistan svekket den amerikanske versjonen av hendelsene på bakken og dokumenterte at sivilbefolkningen led store tap under angrepet.

\section{Mediekrigen}

Irak-krigen 2003 er den mest mediedekkede krigen i historien. ${ }^{\text {I2 }}$ Den viktigste forskjellen i forhold til mediedekningen av tidligere internasjonale konflikter var de nye arabiske mediene. ${ }^{13}$ I kontrast til tidligere internasjonale konflikter, der medienes tilgang til slagmarken var kontrollert og begrenset, dekket rekordmange 3000 mediefolk Irak-krigen fra Irak og nabolandene. Rundt 600 internasjonale journalister inntok Irak innrullert (embedded) med koalisjonsstyrkene, 2000 (unilateral) journalister reiste uavhengig av de militære styrkene, 200 internasjonale journalister dekket krigen fra Bagdad, mens en fjerde gruppe journalister dekket konflikten fra koalisjonsstyrkenes mediesenter Central Command i Qatar. Majoriteten av de arabiske journalistene inne i Irak opererte uavhengig av de militære styrkene.

Det ble tidlig klart at de arabiske satellittkanalene presenterte en annen versjon av hendelsene i Irak enn deres vestlige og amerikanske konkurrenter. Hovedforskjellen var at mens de amerikanske (vestlige) mediene fokuserte på den høyteknologiske amerikanskledede invasjonshæren, fokuserte de arabiske satellittkanalene på den irakiske sivilbefolkningen. Medieanalytikere har pekt på noen karakteristika ved den arabiske krigsdekningen:

I) Alle de arabiske mediene så på koalisjonsstyrkene som en invasjonshær (ikke som "frigjørere") og stilte spørsmål ved om krigen var legitim etter internasjonal lov.

2) De populære talkshowene på de arabiske satellittkanalene fokuserte på å kritisere den amerikanske administrasjonen og inviterte USA-kritiske eksperter og gjester som diskuterte "clash of civilisations' og konspirasjonsteorier.

3) De arabiske kanalene sendte hyppige repriser av den irakiske presidenten Saddam Husseins oppfordring til islamsk hellig krig mot den amerikanske og britiske aggresjonen.

4) Krigsdekningen på de arabiske kanalene prioriterte irakiske sivile tap og 
lidelser, noe ga som det arabiske publikummet en følelse av nærhet, empati og solidaritet med det irakiske folket.

5) De arabiske kanalene fokuserte på den irakiske motstanden i de sørlige områdene i Irak og framhevet de irakiske styrkenes mulighet til å slå tilbake mot koalisjonsstyrkene.

6) De arabiske satellittkanalene formulerte frustrasjonen og usikkerheten som mange følte i regionen rundt Irak og nabolandenes framtid.

\section{Kritikk mot blodige Al Jazeera}

Den amerikanske administrasjonen anklaget flere arabiske kanaler for uansvarlig krigsdekning. Det var likevel Al Jazeera som ble utsatt for den skarpeste kritikken. ${ }^{\text {I4 }}$ Det amerikanske utenriksdepartementet kritiserte kanelen for å gi tendensiøse og feilaktige rapporter fra krigssonen. ${ }^{\text {i5 }}$ Det var særlig tre forhold som provoserte amerikanske myndigheter, som mente at Al Jazeera

I) overdrev amerikanske tap og den irakiske motstanden,

2) var et propagandavåpen for irakiske myndigheter, og

3) oppildnet den arabiske folkeopinionen gjennom å dvele ved og fråtse i irakiske lidelser.

Det arabiske perspektivet var provoserende og skadelig for den amerikanske mediestrategien fordi det underminerte og utfordret den offisielle amerikanske versjonen av det som skjedde i Irak: At den irakiske befolkningen tok imot koalisjonsstyrkene som frigjørere, at høyteknologiske bomber sikret få sivile tap og at krigen hadde bred internasjonal støtte. Siden Vietnam-krigen har det vært sentralt for amerikanske myndigheter å ikke vise likposer av egne falne soldater, men de siste årene har det også blitt viktig å unngå bilder av sivile lidelser. ${ }^{16} \mathrm{Al}$ Jazeera sendte begge deler.

Al Jazeera ble derfor beskyldt for å oppildne den arabiske opinionen mot den usA-ledede invasjonen gjennom sine groteske bilder fra bakken inne i Irak. Nærbildene av ofrene for krigen i Irak var på mange måter lik bildene av palestinske ofre. For Al Jazeera og de andre arabiske satellittkanalene var krigens konsekvenser og sivile ofre de viktigste historiene fra Irak. Kanalens redaksjonelle ledelse sier at de fokuserte på "the sufferings of the people after the attacks and we had many pictures of the people and the buildings that were demolished or destroyed by the attacks or American warplanes and mis-

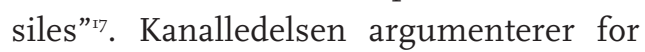
dekningen ved å si at de bare reflekterte krigens grusomheter - som et speil: "People would think it's a clean war, but war is never clean, this is our disposition. We are not trying to infuriate anybody; we're just trying to reflect what's happening on the ground." ${ }^{18}$ Amerikanske myndigheter kritiserte Al Jazeera (og de andre arabiske satellittkanalene i varierende grad) for å bruke tendensiøs terminologi og skape et feilaktig bilde av at amerikanske soldater i Irak skjøt vilt rundt seg. En mediekontakt for arabiske medier i det amerikanske utenriksdepartementet formulerte den amerikanske frustrasjonen på denne måten:

"One example was that several of their reporters in Iraq often cited indiscriminate fire' or charged that 'the Americans were firing indiscriminately.' They didn't produce any proof of this. Rather, this reflected their bias, a 
desire to blame the American side whenever they could [...] Some Arab journalists let their anger about the war influence the way they reported it. ${ }^{19}$

Al Jazeeras svar på kritikken var knapp, men kontant: "Unfortunately, what was happening on the ground [...] did not reflect the American point of view as liberators and so forth. But that's not because we planned it this way, that's because this is the way it happened". ${ }^{\circ}$

Medieanalytikere har pekte på andre forklaringer på hvorfor de arabiske mediene var mer voldelige enn de angloamerikanske: En tvilsom argumentasjon er at den arabiske kulturen er mer vant med vold enn den angloamerikanske og dermed tåler mer voldelige Tv-bilder. Andre har pekt på at de arabiske satellittkanalene er unge og uerfarne, uten etiske retningslinjer og en klar innarbeidet redaksjonell politikk, og at de dermed begår flere etiske overtramp enn sine amerikanske og europeiske kolleger. ${ }^{21}$ Andre har pekt på hensynet til publikum - at mediene reflekterte den arabiske opinionens motstand mot krigen og forventninger til å se blodige bilder fra krigssonen. ${ }^{22}$

\section{Syntetisk TV-krig}

I sterk kontrast til de voldelige bildene på Al Jazeera har studier av krigsdekningen på amerikanske TV-kanaler vist at den krigen som ble vist på amerikanske skjermer var full av action, men uten blod. ${ }^{23} \mathrm{CNN}$, ABC og Fox News sendte for eksempel fem ganger så mange bilder av skudd og kamper enn av sivile ofre.

Resultatet var at de store amerikanske TV-nettverkene formidlet en pyntet, steril og spennende krig, uten å vise krigens kon- sekvenser. ${ }^{24}$ En britisk rapport viser at den store majoriteten britiske journalister i Irak (som reiste sammen med koalisjonsstyrkene) hadde begrenset dekning av sivile skader og ofre. ${ }^{25}$ Dekningen fra de britiske journalistene ga seerne følelsen av å være nær krigshandlingene, men utelot den stygge siden av virkeligheten. De innrullerte britiske reporterne så imidlertid hundrevis av irakiske ofre i felten og noen av dem innrømmer i rapporten at de redigerte bort de døde kroppene.

Det er flere årsaker til at de store angloamerikanske mediene ikke viste flere bilder av sivile lidelser. I en artikkel i American Journalism Review reflekterer en rekke bilderedaktører i store amerikanske medier rundt mangelen på bilder av krigens konsekvenser. ${ }^{26}$ Noen forklaringer går igjen:

I) Mediene begrenset bilder av blod og lidelser av hensyn til publikum (mottakerne hjemme i USA som ikke vil se døde barn til morgenkaffen) og annonsørene i hjemmemarkedet.

2) Majoriteten av amerikanske journalister inntok Irak innrullert med de amerikanske troppene og kunne dermed ikke selv velge hvor de ville stoppe for å ta bilder.

3) De mediene som befant seg inne i Irak ble kontrollert og voktet av irakiske representanter for informasjonsministeriet. Fotografene ble busset rundt av de irakiske myndighetene for å ta bilder av irakiske lidelser, men siden de ofte ikke visste bakgrunnen for skadene lot flere være å sende disse bildene hjem. ${ }^{27}$

4) Flere av de intervjuede redaktørene og fotografene sier de forsøker å unngå de mest direkte bildene av sivile lidelser fordi de mener andre motiv kan illustrere gru- 
somhetene på en mer effektiv måte - de velger bort den direkte volden til fordel for symbolske motiver.

5) Majoriteten av de spurte uttrykker bekymring for en økende konservativ holdning i amerikanske medier - at mediene ikke er villige til å vise like rå bilder som de gjorde for 20,30 og 40 år siden. Noen mener denne mentalitetsendringen kom etter invasjonen i Somalia (da bilder av en død amerikansk soldat som ble dratt gjennom gatene i Mogadishu sjokkerte USA), mens andre mener endringen først kom etter terrorangrepene II. september. Denne konservative holdningen samsvarer med amerikanske myndigheters anstrengelser for å flytte fokus bort fra sivile irakiske lidelser, og kan også være et resultat av politisk press. Det er ikke uvanlig at journalister blir mindre kritiske mot egne myndigheter i en krigssituasjon - tidligere komparative studier har dokumentert at mediene i hovedsak støtter opp om myndighetenes politikk under internasjonale kriser. $^{28}$

\section{En ny enighet?}

Mediedebatten etter krigen har rommet sterke følelser. Debatten er komplisert, fordi den ofte er preget av synsing framfor fakta og forskning. Det finnes ingen tilgjengelige systematiske, komparative undersøkelser av mediedekningen av krigen. Dersom denne typen studier hadde vært tilgjengelig er det likevel er ingen absolutte mål og standarder for hva som er balansert og ansvarlig krigsdekning. Medieteknologien har gjort mediene stadig mer globale, men det finnes ingen globale standarder for å regulere medienes innhold. Debattene preges ofte av journalistiske honnørord og idealer som "ansvarlighet", “objektivitet” og “balanse". ${ }^{29}$ Det er imidlertid mange tolkninger av disse begrepene, og det finnes ingen uavhengige, eksterne og absolutte kriterier for hva som skiller ubalansert krigsdekning fra objektiv dekning. ${ }^{30}$ Som intervjuene med representanter for Al Jazeera og us State Department overfor viser, har de to fundamentalt forskjellige oppfatninger av hva som er ansvarlig og objektiv krigsjournalistikk. De arabiske

\section{m \\ Den krigen som ble vist på \\ amerikanske skjermer var full av action, men uten blod.}

journalistene og amerikanske myndigheter er grunnleggende politisk uenige om den amerikanskledede invasjonen av Irak, men i intervjuene bruker alle "objektivitet" og "ansvarlighet" for å argumentere for sitt syn, uten å utdype hva de legger i begrepene.

Ifølge Vettenranta har TV-nyhetene utviklet seg i retning av en mer tematisk fortelling, en slags serie av nyhetsnoveller der "dårlige" og "gode" karakterer innehar hovedrollene. Temaet tilpasses fiksjonsfortellingenes innhold, der en heltehistorie, en voldsom død, personlige tragedier eller konflikter spiller en sentral rolle. Det anvendes samme formspråk og billedløsninger som i fiksjon og reklamefilm for å forsterke spenning, bevegelse og emosjonell ladning. ${ }^{3 \mathrm{I}}$ Både de vestlige og de arabiske mediene lette etter den beste "menneskelige historien", historien som rører publikum. Hvem som ble presentert som de ideelle, "verdige ofrene" i de menneskelige historiene var imidlertid forskjellig: De arabiske kanalene fokuserte på 
irakiske kvinner og barn, mens de amerikanske kanalene vektla skjebnene til de unge amerikanske soldatene (med den dramatiske, men sterkt redigerte historien om Private Jessica Lynch som den viktigste enkelthistorien).

Siden det ikke finnes noen absolutte regler for hvor voldelige bilder mediene kan vise, ble beslutninger om hvor mye blod og lidelser mediene kunne sende fra Irak ble ofte tatt på magefølelsen. Fotoredaktørene og journalistene intervjuet i American Journalism Review vektlegger at de ikke hadde noen absolutte forbud mot blodige bilder, men at bildevalgene ble preget av rekken av faktorer nevnt ovenfor. Majoriteten av de spurte sier imidlertid at de burde ha sendt råere og mer direkte bilder av konsekvensen av krigen.

I 2004, etter hvert som den irakiske motstanden ble sterkere, endret også de amerikanske TV-bildene karakter og ble stadig mer blodige. Opprøret i Falluja, kister med falne amerikanske soldater og de sjokkerende bildene fra fangetorturen i Abu Graib-fengselet er blitt tolket som symboler på en mer kritisk og rå amerikansk mediedekning fra Irak.

Samtidig er det tilløp til endringer i de arabiske mediene: Al Arabiyya Channel endret sin redaksjonelle linje i 2004, og Al Jazeera vedtok å formalisere sine etiske retningslinjer sommeren 2004. Er dette tegn på en bredere konsensus om hva som er ansvarlig og kritisk krigsdekning? Det er for tidlig å si. Zelitzer (2004) understreker at de nye voldelige bildene fra Irak ikke nødvendigvis symboliserer en ny holdning blant journalister, men at de kan forstås som et resultat av et økende press utenfra. De mest kontroversielle bildene som brøt tabuer i journalistikken, for eksempel av kister kledd i amerikanske flagg og ydmykelsene fra Abu Graib, ble ikke tatt av profesjonelle pressefotografer, men av militært personnel som senere lekket bildene til mediene: "There were lots of independent forces moving the question of what is a good war image of this particular war in directions that journalism had not necessarily taken us."

\section{$\cdot f \cdot$}

I Slapgard 2003:I49, Sigrun Slapgard (2003): «Krig og løgn», Gyldendal

2 Dette avsnittet om medievold bygger på Soilikki Vettenranta: «De unge og katastrofenyheter» (2005), Abstrakt Forlag

3 Strukturell vold kan sees som den skade som oppstår når tilstanden til sosiale og kulturelle institusjoner, eller mangelen på slike, hindrer samfunnets medlemmer i å realisere sitt potensiale. Weigert, Kathleen (I999): "Structural Violence" i Encyclopedia of Violence, Peace \& Conflict. Vol. 3, Academic Press.

4 Eide, Elisabeth (2004): "Warfare and Dual Vision in Media Discourse", i Nohrstedt, Stig A. og Rune Ottosen (red.) «U.S. and the Others. Global Media Images on 'The War on Terror'», Göteborg: NORDICOM

5 Höijer, Nohrstedt og Ottosen 2004:II, "Introduction" i Stig A. Nohrstedt og Rune Ottosen (red.): «U.S. and the Others. Global Media Images on 'The War on Terror'» (2004), Göteborg: NORDICOM

6 Se for eksempel Stig Nohrstedt, Birgitta Höijer og Rune Ottosen: "Kosovokonflikten, mediarna og medlidandet" (2002), Styrelsen for psykologisk Försvar, Rapport 190

7 Cronström 2000, Höijer 1994;1996 i Nohrstedt, Höijer og Ottosen 2004

8 Vettenranta 2005:39

9 Ibid.:24

Io Hickey, Neil (2002): “Access Denied. The Pentagon's War reporting Rules are the Toughest Ever", Columbia Journalism Review, January / February 2002, tilgjengelig på: http://www.cjr.org/year/o2/I/hickey.asp

II Et eksempel er CNN International der kanalens styreformann påla redaksjonen å "balansere" alle bilder av afghanske sivile ofre med bilder fra terrorangrepene II. september slik at ikke sympatien for de afghanske ofrene skulle dominere.

I2 Tumber, Howard og Jerry Palmer (2003): «Media at War. The Iraqi Crisis», London / Thousand Oaks / New Delhi: SAGE Publications 
I3 White, Aidan (2003): “Justice Denied On The Road To Baghdad. Safety of Journalists and the Killing of Media staff During the Iraq War", International Federation of Journalists (IFJ) oktober 2003, tilgjengelig på: http://www.ifj.org/pdfs/iraqreport2003.pdf

I4 Intervjuene med forskere, representanter for $\mathrm{Al}$ Jazeera Channel og representanter for US State Department brukt i denne artikkelen er gjort i forbindelse med min hovedfagsoppgav "Courting, criticism, censorship and bombs: A study of the relationship between the Al Jazeera Channel and the US administration during the war in Iraq 2003", ved Institutt for medier og kommunikasjon / Avdeling for journalistikk, bibliotek- og informasjonsfag, Universitetet i Oslo / Høgskolen i Oslo, 2004. Oppgaven ble utgitt som rapport ved Høgskolen i Oslo i mai 2005.

I5 us Arab Media Officer, intervjuet av forfatteren I5. mars 2004, Washington D.C. USA

I6 Höijer, Nohrstedt og Ottosen 2004:I5

I7 Shouli, Saeed, Deputy Editor-in-Chief, Al Jazeera Channel, intervjuet av forfatteren 9. oktober 2003, Al Jazeera Headquarter, Doha, Qatar

I8 Ballout, Jihad Ali, Section Head Communications \& Media Relations, Al Jazeera Channel, intervjuet av forfatteren 5. oktober 2003 , I3. oktober 2003 og I5. oktober 2003, på Al Jazeera Marketing Office, Doha, Qatar

I9 Us Arab Media Officer 15. mars 2004

20 Ballout 5. oktober 2003

2I Zayani, Dr. Mohammed, American University of Sharjah, intervjuet av forfatteren 26. oktober 2003, på American University of Sharjah, Forente Arabiske Emirater

22 Miladi, Noureddine, University of Westminster, intervjuet av forfatteren 26. november 2003 på University of West minster, London, Storbritannia

23 Se for eksempel Aday, Sean (2004): "The Real War Will Never get On Television", paper International Studies Association, I8.-20. mars 2004, Montreal, Canada

24 Aday 2004:I4

25 Lewis, Justin, Terry Threadgold, Rod Brookes, Nick Mosdell, Kirsten Brander, Sadie Clifford, Ehab Bessaiso og Zahera Harb (2004): “TOO CLOSE FOR COMFORT?: The role of embedded reporting during the 2003 Iraq war", Summary report, Cardiff University, tilgjengelig på: http://www.soc.surrey.ac.uk/warandmedia/documents/ comfort_summary.doc

26 Robertson, Lori (2004): "Images of War", American Journalism Review, October/November 2004

27 Et viktig unntak var bildene av den skadde irakiske gutten Ali Ismail Abbas som ble trykket i Time Magazine. Bildene av den fortvilte gutten ble selve symbolet på irakiske barns lidelser og oppmerksomheten reddet livet til Ali som senere fikk behandling og nå er bosatt i USA. Det er fremdeles usikkert om det var irakiske antiluftskyts eller amerikanske bomber som skadet Ali.

28 Se for eksempel Nohrstedt, Stig Arne og Rune Ottosen (2000): "Studying the Media Gulf War", in Nohrstedt, Stig
Arne og Rune Ottosen (reds.): «Journalism and the New World Order. Gulf War, National News and Globalization», Göteborg: NORDICOM

29 Det klassiske journalistiske objektivitetsidealet handler i hovedsak om å vektlegge fakta, nøytralitet, nøyaktighet, relevans og upartiskhet. De fleste journalister er i dag enige om at idealet er viktig, men umulig å etterleve i det daglige arbeidet.

30 Tumber og Palmer 2003:92

3I Vettenranta 2005:I7

32 Zelizer til Robertson 2004 